\title{
Inappropriate implantable cardioverter defibrillator shocks-incidence, effect, and implications for driver licensing
}

\author{
Eiichi Watanabe $^{1}$ - Katsunori Okajima ${ }^{2}$ - Akira Shimane ${ }^{2} \cdot$ Tomoya Ozawa $^{3}$. \\ Tetsuyuki Manaka ${ }^{4}$ - Itsuro Morishima ${ }^{5}$ - Toru Asai ${ }^{6} \cdot$ Masahiko Takagi $^{7}$. \\ Toshihiro Honda ${ }^{8}$ - Atsunobu Kasai ${ }^{9}$ Eitaro Fujii ${ }^{10}$ - Kohei Yamashiro ${ }^{11}$. \\ Ritsuko Kohno ${ }^{12}$ - Haruhiko Abe ${ }^{12}$. Takashi Noda ${ }^{13}$. Takashi Kurita ${ }^{14}$. \\ Shigeyuki Watanabe ${ }^{15}$ - Hiroya Ohmori ${ }^{16}$. Takashi Nitta ${ }^{16}$. Yoshifusa Aizawa ${ }^{17}$. \\ Ken Kiyono ${ }^{18}$ - Ken Okumura ${ }^{19}$
}

Received: 3 April 2017 / Accepted: 10 July 2017 / Published online: 20 July 2017

(C) The Author(s) 2017. This article is an open access publication

\begin{abstract}
Purpose Patients with implantable cardioverter defibrillators (ICDs) have an ongoing risk of sudden incapacitation that may cause traffic accidents. However, there are limited data on the magnitude of this risk after inappropriate ICD
\end{abstract}

This study was registered in the University Hospital Medical Information Network Clinical Trials Registry (UMIN-CTR) 000025995.

Electronic supplementary material The online version of this article (doi:10.1007/s10840-017-0272-4) contains supplementary material, which is available to authorized users.

Eiichi Watanabe

enwatan@fujita-hu.ac.jp

1 Department of Cardiology, Fujita Health University School of Medicine, Dengakugakubo 1-98, Kutsukake-cho,

Toyoake, Aichi 470-1192, Japan

2 Department of Cardiology, Himeji Cardiovascular Center, Himeji, Japan

3 Department of Cardiovascular and Respiratory Medicine, Shiga University of Medical Science, Otsu, Japan

4 Department of Cardiology, Tokyo Women's Medical University, Tokyo, Japan

5 Department of Cardiology, Ogaki Municipal Hospital, Ogaki, Japan

6 Department of Cardiology, Ichinomiya Municipal Hospital, Ichinomiya, Japan

7 Department of Cardiovascular Medicine, Osaka City University Graduate School of Medicine, Osaka, Japan

8 Division of Cardiology, Saiseikai Kumamoto Hospital Cardiovascular Center, Kumamoto, Japan

9 Department of Cardiology, Ise Red Cross Hospital, Ise, Japan therapies. We studied the rate of syncope associated with inappropriate ICD therapies to provide a scientific basis for formulating driving restrictions.

Methods Inappropriate ICD therapy event data between 1997 and 2014 from 50 Japanese institutions were analyzed

10 Department of Cardiology and Nephrology, Mie University Graduate School of Medicine, Tsu, Japan

11 Cardiovascular Medicine, Toyohashi Heart Center, Toyohashi, Japan

12

Department of Heart Rhythm Management, University of Occupational and Environmental Health, Kitakyushu, Japan

13 Department of Cardiovascular Medicine, National Cerebral and Cardiovascular Center, Suita, Japan

14 Department of Medicine, Faculty of Medicine, Division of Cardiovascular Center, Kinki University School of Medicine, Osaka-Sayama, Osaka, Japan

15 Department of Cardiology, Tsukuba University Hospital Mito Education and Training Center, Mito, Japan

16 Department of Cardiovascular Surgery, Nippon Medical School, Tokyo, Japan

17 Department of Research and Development, Tachikawa Medical Center, Nagaoka, Japan

18 Division of Bioengineering, Graduate School of Engineering Science, Osaka University, Toyonaka, Japan

19 Department of Cardiology, Hirosaki University Graduate School of Medicine, Hirosaki, Japan 
retrospectively. The annual risk of harm (RH) to others posed by a driver with an ICD was calculated for private driving habits. We used a commonly employed annual RH to others of 5 in 100,000 $(0.005 \%)$ as an acceptable risk threshold.

Results Of the 4089 patients, 772 inappropriate ICD therapies occurred in 417 patients (age $61 \pm 15$ years, $74 \%$ male, and $65 \%$ secondary prevention). Patients experiencing inappropriate therapies had a mean number of $1.8 \pm 1.5$ therapy episodes during a median follow-up period of 3.9 years. No significant differences were found in the age, sex, or number of inappropriate therapies between patients receiving ICDs for primary or secondary prevention. Only three patients $(0.7 \%)$ experienced syncope associated with inappropriate therapies. The maximum annual RH to others after the first therapy in primary and secondary prevention patients was calculated to be 0.11 in 100,000 and 0.12 in 100,000 , respectively.

Conclusions We found that the annual RH from driving was far below the commonly cited acceptable risk threshold. Our data provide useful information to supplement current recommendations on driving restrictions in ICD patients with private driving habits.

Keywords Arrhythmia $\cdot$ Syncope $\cdot$ Driving $\cdot$ Implantable cardioverter defibrillator $\cdot$ Prevention

\section{Introduction}

Implantable cardioverter defibrillators (ICDs) improve survival in patients at risk of sudden cardiac death [1]. However, these patients have an ongoing risk of sudden incapacitation that may cause harm to themselves and others when driving [2-10]. An obvious concern is the effect of arrhythmias and/or discharges of devices on a patient's level of consciousness and ability to drive. According to the literature, the rate of syncope or loss of consciousness associated with appropriate ICD therapy varies from 2 to $15 \%[5-7,11-13]$. Approximately 10 $20 \%$ of ICD patients experience inappropriate ICD therapies (therapies delivered for non-ventricular arrhythmias) according to the previous reports [11,14-16]; however, few studies have studied the rate of syncope or loss of consciousness as a result of inappropriate therapy. Thus, a large variation exists among countries concerning driving restrictions following inappropriate ICD therapies [17-22].

Currently, inappropriate therapy reduction programming, including higher detection rates, longer detection intervals, and optimized supraventricular tachycardia discriminators, have been reported to reduce ICD shocks without increasing the arrhythmic syncope among ICD patients for primary prevention [12, 23-26]. Although such shock reduction programming is beneficial, it may take time for this programming to spread to the actual clinical setting.
It is critical to collect data regarding the rate of the incidence that lead to impaired driving after inappropriate ICD therapy to prevent serious driving accidents, while at the same time avoiding unnecessary driving restrictions on patients with ICDs for both primary prevention and secondary prevention. We set two objectives: (1) to identify the rate and causes of syncopal episodes associated with inappropriate ICD therapy and (2) to calculate the risk of harm to other road users in order to provide a scientific basis for driving restrictions in ICD patients.

\section{Methods}

We analyzed the inappropriate ICD therapy event data between 1997 and 2014. This retrospective, observational, non-randomized study was conducted at 50 institutions participating in prospective ICD studies [27, 28] and Japanese Heart Rhythm Society board-certified institutions (participants' list in Supplementary File). The ethics committee of each institution approved the study protocol, and all patients gave their written informed consent. The study complied with the Declaration of Helsinki and its later amendments or comparable ethical standards.

\subsection{Database and ICD therapy event analysis}

The Japanese Heart Rhythm Society board-certified electrophysiologists at the 50 institutions were asked to submit a total number of ICD implantation and case report form for the patients who had inappropriate therapies after the initial implantation. It included the patient demographics, underlying disease, comorbidities, ventricular function, and medications. The data regarding the ICD included the date and indication for the implantation, date and time of the onset of any appropriate or inappropriate therapies, cause, and type of inappropriate therapy, in addition to the activity associated with the inappropriate therapy. Finally, we asked them whether or not each inappropriate ICD therapy was associated with syncope. The implanted system manufacturers were Biotronik (Berlin, Germany), Boston Scientific (St. Paul, MN, USA), Medtronic (Minneapolis, MN, USA), and St. Jude Medical (St. Paul, MN, USA). All ICDs in this study were equipped with intracardiac electrogram (EGM) storage. The ICDs were interrogated every 3 months and when clinically appropriate, such as after a delivered therapy. ICD therapies were defined as either antitachycardia pacing (ATP) or shock therapy, including cardioversion and defibrillation. Therapies were categorized as appropriate when they occurred in response to ventricular tachycardia (VT) or ventricular fibrillation (VF) and as inappropriate. An inappropriate therapy included therapy for atrial fibrillation (AF), supraventricular tachycardias (SVTs), including sinus tachycardia, abnormal sensing ( $\mathrm{T}$ wave 
oversensing, myopotential, and electromagnetic interference, other than oversensing of short VV intervals related to lead fractures), and lead failures [11, 14]. The determination of an inappropriate or appropriate ICD therapy was made by the electrophysiologists at the participating institutions and was not adjudicated by independent electrophysiologists. The ICD programming was left to the discretion of each investigator. We did not exclude patients in whom the generator or leads were replaced. A syncopal event associated with inappropriate therapies was the primary endpoint and was defined as a total loss of consciousness with spontaneous recovery. These events were identified through reviewing the medical charts. We excluded syncopal episodes not related to inappropriate therapies. The time to the first inappropriate therapy was measured from the date of the ICD implant to the date of an inappropriate ICD therapy. The time to the second therapy was measured from the date of the first inappropriate ICD therapy to the date of the second inappropriate therapy. Regarding the second therapy analysis, only subsequent inappropriate therapies occurring $>24 \mathrm{~h}$ after the first inappropriate therapy were considered to be second therapies.

\subsection{Risk assessment}

The Canadian Cardiovascular Society Consensus Conference published a "risk of harm" (RH) formula to quantify the level of risk to drivers with ICDs according to the Ontario Road Safety Annual Report [8, 29]. It has been used in several other reports $[5,9,16,19,22,30]$. The following equation is the risk of harm formula: $\mathrm{RH}=\mathrm{TD} \times \mathrm{V} \times \mathrm{SCI} \times$ Ac, which calculates the yearly RH to other road users posed by a driver with heart disease; TD equals the proportion of time the patient spends driving during the year ( 0.04 for private drivers, 0.25 for commercial drivers); $\mathrm{V}$ is a vehicle-specific constant based on the type of vehicle driven (1.0 for a commercial heavy truck and 0.28 for a standard-size passenger car); SCI is the annual probability of sudden incapacitation, and Ac is the probability of injury or an accident after the SCI. We used an Ac of 0.02 according to the previous studies $[2,3]$. In this study, the yearly risk of SCI was calculated to be 0.13 for primary prevention and 0.14 for secondary prevention, respectively, based on the incidence of syncope associated with inappropriate ICD therapies (i.e., 1 out of 144 patients for primary prevention and 2 out of 273 patients for secondary prevention) divided by the mean follow-up period of 5.3 years. Standard errors were derived from the binomial distribution, and the 95\% confidence interval was constructed with the normal approximation according to the previous study [9]. We calculated the RH after the first and second shocks, respectively, along with the previous study [9]. An acceptable RH was defined to be $5 / 100,000$ or $0.005 \%[8,9,16]$.

\subsection{Statistical analysis}

The $\chi^{2}$ test or Fisher exact test was used for categorical data, and a Student's $t$ test or Mann-Whitney test was used for continuous variables. Comparisons of the time to therapy were made using the Kaplan-Meier method and compared with the log-rank test. Quantitative data are expressed as the mean \pm standard deviation (SD) values or median with an inter-quartile range. A two-tailed $p$ value of $<0.05$ was considered significant. Statistical analyses were performed using JMP 10.0.2 software (SAS Institute, USA) and R Project for Statistical Computing 3.2.2.

\section{Results}

\subsection{Clinical characteristics of the patients}

The baseline characteristics of the patients are summarized in Table 1. Of the 4089 patients, 772 inappropriate ICD therapies occurred in 417 patients (age $61 \pm 15$ years, $74 \%$ male, and the reason for the implantation was secondary prevention in $65 \%$ ). No significant differences were noted in the age, sex, and baseline cardiac rhythms between the primary and secondary prevention patients. There was a significant difference in the prevalence of single-chamber or dual-chamber ICDs and cardiac resynchronization therapy with defibrillators (CRT-Ds) between the primary and secondary prevention patients. Coronary artery disease was observed in $20 \%$ of patients, and the mean left ventricular ejection fraction was $45 \%$. The median date of the implantation was November 2010, and approximately $90 \%$ of the patients received ICDs after 2005 (supplementary figure).

\subsection{Inappropriate ICD therapies}

Patients experiencing inappropriate therapies had a mean number of $1.8 \pm 1.5$ inappropriate therapy episodes during a median follow-up period of 3.9 [inter-quartile range, 3.1 to 6.8] years (Table 2). A total of 169 patients (41\%) had more than 1 inappropriate therapy, with a maximum of 15 inappropriate therapies. There were no significant differences in the number of inappropriate therapies between the primary prevention and secondary prevention patients $(1.7 \pm 1.7$ vs. $1.9 \pm 1.6, p=0.13)$. The first inappropriate therapy occurred a median of 382 days after the implantation (inter-quartile range, 85 to 841 days). The median time between the first and second inappropriate therapies was 117 days (inter-quartile range, 25 to 408 days). There was a significant difference in the time to the first inappropriate therapy between the primary prevention and secondary prevention patients (median 314 vs. 401 days, $p<0.01)$. The time-dependent occurrence of 
Table 1 Clinical characteristics of the patients

\begin{tabular}{|c|c|c|c|c|}
\hline Characteristic & $\begin{array}{l}\text { All patients } \\
(n=417)\end{array}$ & $\begin{array}{l}\text { Primary prevention } \\
(n=144)\end{array}$ & $\begin{array}{l}\text { Secondary prevention } \\
(n=273)\end{array}$ & $p$ value \\
\hline Age (years) & $61 \pm 15$ & $60 \pm 15$ & $61 \pm 16$ & 0.70 \\
\hline Male, $n(\%)$ & 309 (74) & $105(73)$ & $204(76)$ & 0.47 \\
\hline Baseline rhythm, $n(\%)$ & & & & 0.39 \\
\hline Sinus rhythm & $333(80)$ & $118(82)$ & $215(80)$ & \\
\hline Atrial fibrillation & $71(17)$ & $24(17)$ & $47(18)$ & \\
\hline Pacemaker escape rhythm & $8(2)$ & $1(0.7)$ & $7(3)$ & \\
\hline Devices, $n(\%)$ & & & & $<0.001$ \\
\hline Single-chamber ICD & $54(13)$ & $17(12)$ & $37(14)$ & \\
\hline Dual-chamber ICD & $284(68)$ & $81(56)$ & $203(74)$ & \\
\hline CRT-D & $79(19)$ & $47(33)$ & $32(12)$ & \\
\hline \multicolumn{5}{|l|}{ Underlying heart disease, $n(\%)$} \\
\hline Coronary artery disease & $84(20)$ & $19(13)$ & $65(24)$ & $<0.01$ \\
\hline Brugada syndrome & $31(7)$ & $16(11)$ & $15(6)$ & 0.04 \\
\hline Dilated cardiomyopathy & $95(23)$ & $52(36)$ & $43(16)$ & $<0.001$ \\
\hline Hypertrophic cardiomyopathy & $52(12)$ & $20(14)$ & $32(12)$ & 0.57 \\
\hline Sarcoidosis & $17(4)$ & $5(3)$ & $12(4)$ & 0.62 \\
\hline Amyloidosis & $1(0.2)$ & $0(0)$ & $1(0.3)$ & 0.75 \\
\hline Long-QT syndrome & $5(1)$ & $2(1.4)$ & $3(1.1)$ & 0.81 \\
\hline ARVC & $15(2)$ & $1(0.7)$ & $14(5)$ & 0.04 \\
\hline VHD & $9(2)$ & $2(1.4)$ & $7(3)$ & 0.64 \\
\hline \multicolumn{5}{|l|}{ Medical comorbidities, $n(\%)$} \\
\hline Hypertension & $160(39)$ & $56(39)$ & $104(39)$ & 0.99 \\
\hline Diabetes & $69(17)$ & $20(14)$ & $49(18)$ & 0.25 \\
\hline Stroke & $16(3)$ & $11(8)$ & $5(1.5)$ & $<0.01$ \\
\hline Chronic kidney disease & $43(10)$ & $10(7)$ & $33(32)$ & 0.09 \\
\hline Left ventricular ejection fraction $(\%)$ & $45 \pm 17$ & $42 \pm 19$ & $47 \pm 16$ & $<0.05$ \\
\hline \multicolumn{5}{|l|}{ Medications, $n(\%)$} \\
\hline Beta-blocker & $268(64)$ & $93(65)$ & $175(65)$ & 0.88 \\
\hline ACE-I/ARB & $216(52)$ & $82(57)$ & $134(50)$ & 0.18 \\
\hline Amiodarone & $144(35)$ & $36(25)$ & $108(40)$ & $<0.01$ \\
\hline Sotalol & $18(4)$ & $3(2)$ & $15(6)$ & 0.09 \\
\hline Aspirin & $82(20)$ & $19(13)$ & $63(24)$ & 0.01 \\
\hline Warfarin & $158(38)$ & $53(37)$ & $105(38)$ & 0.63 \\
\hline
\end{tabular}

Data represent the number, frequency, or means $\pm \mathrm{SD}$. Chronic kidney disease $=$ estimated glomerular filtration rate $<60 \mathrm{~mL} / \mathrm{min} / 1.73 \mathrm{~m}{ }^{2}$

ICD implantable cardioverter defibrillator, $C R T-D$ cardiac resynchronization therapy with defibrillator, $A R V C$ arrhythmogenic right ventricular cardiomyopathy, $V H D$ valvular heart disease, $A C E-I$ angiotensin-converting enzyme inhibitor, $A R B$ angiotensin II type 1 receptor blocker

the first and second inappropriate therapies for primary and secondary prevention is shown in Fig. 1.

The total number of inappropriate therapies by the mechanism rather than by the patient and the subclassifications of inappropriate therapies are shown in Table 3. SVT was the most common mechanism for an inappropriate therapy (63\%), followed by AF (27\%) and abnormal sensing (7\%). A small percentage of rhythms triggering ICD therapies (2\%) were unclassified. There was no significant difference in the type of inappropriate therapies between the primary and secondary prevention patients. In this study, 373 patients $(89 \%)$ had one mechanism of inappropriate therapy, 38 (9\%) had two mechanisms, and $6(1 \%)$ experienced all three mechanisms.

\subsection{Rate of syncope and risk of harm}

Three patients $(0.7 \%)$ experienced syncope associated with inappropriate therapies. Two of these patients had syncope, one during an SVT and the other during sinus rhythm and 
Table 2 Inappropriate ICD therapy and rate of syncope

\begin{tabular}{lllll}
\hline & $\begin{array}{l}\text { All patients } \\
(n=417)\end{array}$ & $\begin{array}{l}\text { Primary prevention } \\
(n=144)\end{array}$ & $\begin{array}{l}\text { Secondary prevention } \\
(n=273)\end{array}$ & $p$ value \\
\hline $\begin{array}{l}\text { Inappropriate therapy } \\
\text { episodes, } n(\%)\end{array}$ & $1.8 \pm 1.5$ & $1.7 \pm 1.7$ & $1.9 \pm 1.6$ & 0.13 \\
$\begin{array}{c}\text { Number of inappropriate } \\
\text { therapy episodes, } n(\%)\end{array}$ & $248(59)$ & $88(61)$ & $160(59)$ & \\
1 & $102(24)$ & $40(28)$ & $62(23)$ & $19(7)$ \\
2 & $24(6)$ & $5(3)$ & $13(5)$ & $6(2)$ \\
3 & $18(4)$ & $5(3)$ & $12(4)$ & $108(40)$ \\
4 & $8(2)$ & $2(1)$ & $2(0.7)$ & 0.03 \\
5 & $17(4)$ & $5(3)$ & & 0.96 \\
$\geq 6$ & $150(36)$ & $42(29)$ & $1(0.7)$ & \\
Appropriate therapy & $3(0.7)$ & & & \\
episodes, $n(\%)$ & Syncope, $n(\%)$ & & & \\
\hline
\end{tabular}

Data represent the number, frequency, or means $\pm \mathrm{SD}$ oversensing, both of which degenerated to $\mathrm{VF}$, as a result of the inappropriate therapies. The latter case is presented in Fig. 2. The remaining patient who was implanted with a dualchamber ICD for primary prevention had syncope due to AF with a rapid ventricular response, which was terminated by shock therapy. These three syncope patients did not have any further episodes of syncope with ICD therapies. In this study, only one patient experienced a shock for SVT while driving a motor vehicle, but did not experience any syncope nor cause an accident on the road. Further, no patients had any syncope or deaths related to motor vehicle accidents. For private driving habits, the maximum annual RH of the first and second inappropriate therapies in the primary prevention patients was calculated as 0.12 in 100,000 and 0.15 in 100,000 , respectively. Also, that in the secondary prevention patients was calculated as 0.12 in 100,000 and 0.16 in 100,000, respectively. These RH values were found to be far below the acceptable level of 5 in 100,000 (Fig. 3).

(a)



Fig. 1 The time-dependent occurrence of an inappropriate therapy. a Primary prevention. The first inappropriate therapy occurred at a median time of 314 days (inter-quartile range, 64 to 697 days) after the implantation. The median time between the first and second inappropriate

\section{Discussion}

In this study, we presented data on the RH posed by individuals with ICDs toward other users of the road based on the rate of syncope associated with an inappropriate ICD therapy. We showed that the annual $\mathrm{RH}$ from driving was far below the commonly cited acceptable risk threshold. Our data may provide useful information to supplement the current recommendations on driving restrictions in ICD patients with private driving habits.

The mean age of the study patients was 61 years, which was comparable to a previous observational study by van Ree et al. [15] (mean age, 61 years) that characterized inappropriate ICD therapies and a recent randomized study of the MADIT-RIT trial [25] (mean age of the conventional group, 63 years), but somewhat older than that in the subgroup analysis of the SCD-HeFT trial [31] (median age, 57 years). Further, in this study, the rate of single-chamber ICDs in

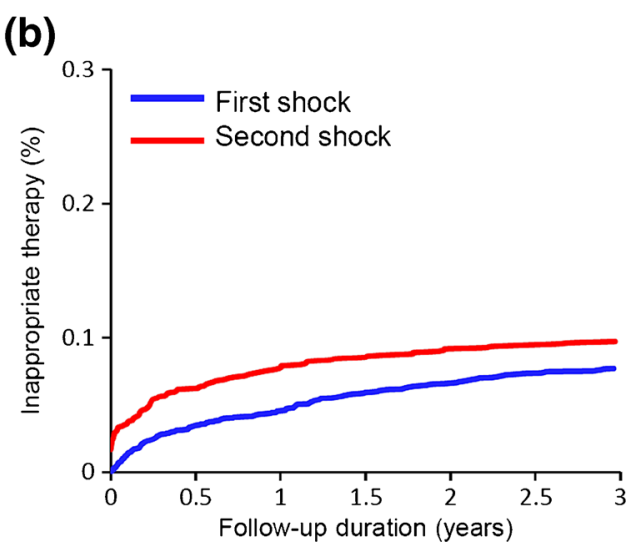

therapies was 85 days. b Secondary prevention. The first inappropriate therapy occurred at a median time of 401 days (inter-quartile range 97 to 1040 days) after the implantation. The median time between the first and second inappropriate therapies was 123 days 
Table 3 Inappropriate ICD therapy episodes

\begin{tabular}{|c|c|c|c|c|}
\hline & $\begin{array}{l}\text { Total therapy episodes } \\
(n=772)\end{array}$ & $\begin{array}{l}\text { Primary prevention } \\
(n=251)\end{array}$ & $\begin{array}{l}\text { Secondary prevention } \\
(n=521)\end{array}$ & $p$ value \\
\hline \multicolumn{5}{|c|}{ Cause of inappropriate therapy, $n(\%)$} \\
\hline SVT & $483(63)$ & $152(61)$ & $331(64)$ & 0.42 \\
\hline $\mathrm{AF}$ & $207(27)$ & $71(28)$ & $136(26)$ & 0.52 \\
\hline Abnormal sensing & $52(7)$ & $21(8)$ & $31(6)$ & 0.21 \\
\hline Lead failure & $15(2)$ & $5(2)$ & $10(2)$ & 0.95 \\
\hline Unclassified & $15(2)$ & $2(1)$ & $13(3)$ & 0.11 \\
\hline \multicolumn{5}{|c|}{ Type of inappropriate therapy, $n(\%)$} \\
\hline ATP only & $356(46)$ & $115(46)$ & $241(46)$ & 0.91 \\
\hline Shock only & $188(24)$ & $64(25)$ & $124(24)$ & 0.61 \\
\hline $\mathrm{ATP}+$ shock & $228(30)$ & $72(29)$ & $156(30)$ & 0.72 \\
\hline $\begin{array}{l}\text { Activity associated with the } \\
\text { inappropriate therapy, } n(\%)\end{array}$ & & & & 0.13 \\
\hline Sleeping & $28(4)$ & $10(4)$ & $18(4)$ & \\
\hline Sedentary/awake & $302(39)$ & $112(45)$ & $190(36)$ & \\
\hline Limited exercise & $59(8)$ & $23(9)$ & $36(7)$ & \\
\hline Moderate exercise & $157(20)$ & $45(18)$ & $112(21)$ & \\
\hline Driving & $1(0.1)$ & $1(0.4)$ & $0(0)$ & \\
\hline Drinking & $11(1)$ & $3(1)$ & $8(2)$ & \\
\hline Bathing & $16(2)$ & $3(1)$ & $13(3)$ & \\
\hline Unknown & $198(26)$ & $54(22)$ & $144(28)$ & \\
\hline \multicolumn{5}{|l|}{$\begin{array}{l}\text { Inappropriate therapy-induced } \\
\text { ventricular arrhythmia, } n(\%)\end{array}$} \\
\hline VT & $5(0.6)$ & $1(0.4)$ & $4(0.8)$ & 0.54 \\
\hline VF & $12(2)$ & $4(2)$ & $8(2)$ & 0.95 \\
\hline
\end{tabular}

Data represent the number and frequency

$S V T$ supraventricular tachycardia, $A F$ atrial fibrillation, $A T P$ antitachycardia pacing, $V T$ ventricular tachycardia, $V F$ ventricular fibrillation

primary prevention was $12 \%$, which was lower than that in the recent ICD registries ranging from 23 to $39 \%$ [32, 33]. The potential explanation for the differences in the age and lower use of single-chamber ICDs for primary prevention may be found within the evolving and expanding guidelines for the implantation of ICDs over a 17 -year period, device programming, and (non-) pharmacological treatment of arrhythmias or other unknown confounders. Our data indicated that the most common cause of inappropriate therapy was SVT, which included sinus tachycardia, followed by AF. We made every effort to identify the mechanism of the SVT, but missing or incomplete data hampered the complete clarification of the SVT.

There is a wide variation in the driving restrictions after inappropriate ICD therapies among countries. In the USA, scientific statements showed that a private driver must refrain from driving for 6 months after receiving any ICD therapy, regardless of whether the therapy is appropriate or inappropriate $[17,18]$. In the UK, a patient must cease from driving for 1 month after the cause of inappropriate therapy has been corrected [20]. In Europe, no time frame is set; however, the patient is not allowed to drive until the cause of the inappropriate therapy is resolved [19]. According to the previous Japanese driving restrictions, ICD patients were advised not to drive for 12 months after receiving either appropriate or inappropriate therapies [21], but from 2017, ICD patients do not have to refrain from driving after receiving an inappropriate ICD therapy if it is not associated with a loss of consciousness [22].

Two recent studies calculated the RH using the data on the incidence of syncope associated with appropriate therapy [9, 30]. Merchant et al. showed that if they used a contemporary estimate for syncope associated with an appropriate ICD shock of $14 \%$, the RH fell below the threshold at 1 month after an initial shock [30]. Few reports, however, have calculated the RH because the data on the rate of inappropriate ICD therapy-related syncope are scarce. To the best of our knowledge, for the first time, we have provided data demonstrating that the maximum annual RH posed by ICD drivers to other users of the road after a first therapy for primary and second prevention was far below the cutoff level proposed by the Canadian consensus [8]. The RH formula was developed in 

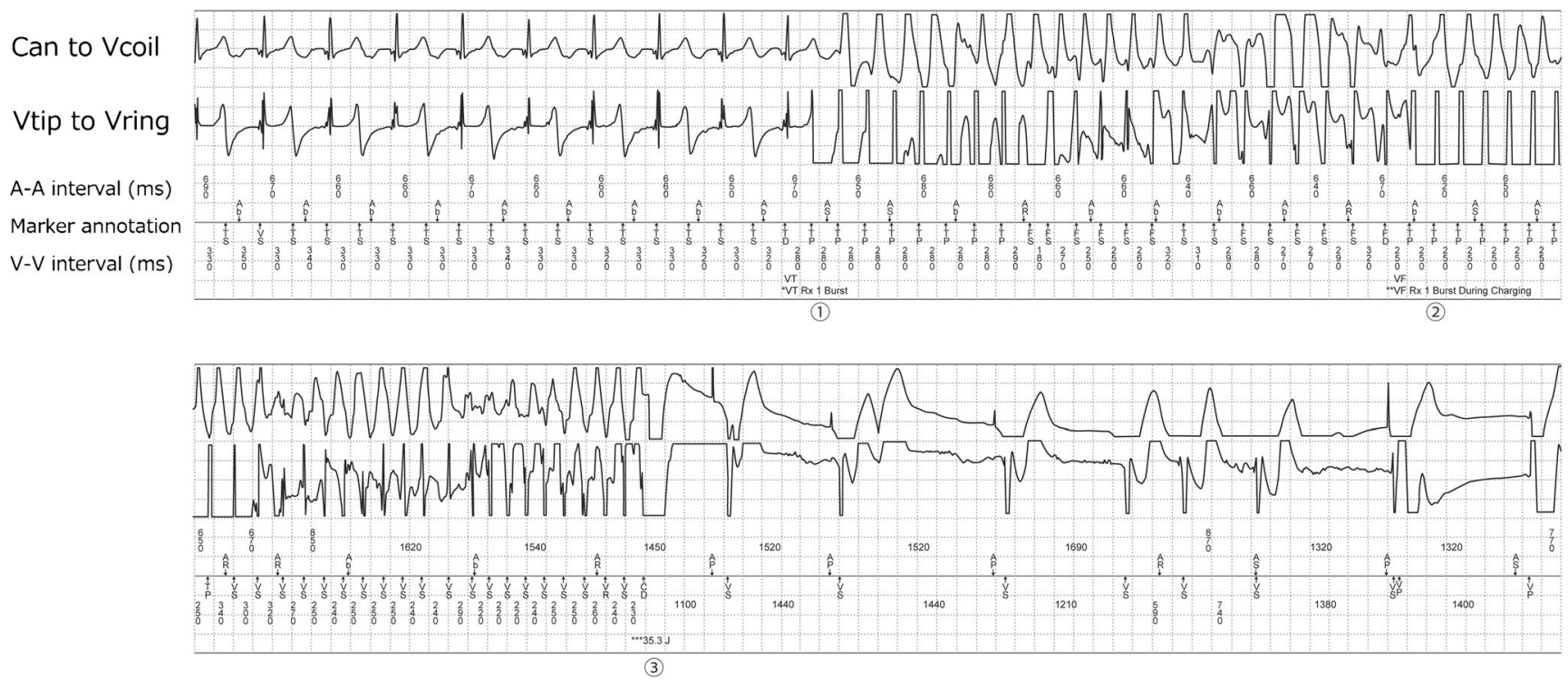

Fig. 2 An ICD-stored intracardiac electrogram. A 61-year-old man that had dilated cardiomyopathy and chronic hemodialysis received an ICD (Secura DR, Medtronic) for secondary prevention in 2009. In 2011, he had chest discomfort and unconsciousness, followed by a shock delivery at work. A stored electrogram shows that the sinus tachycardia with $\mathrm{T}$ wave oversensing with a cycle length of $330 \mathrm{~ms}$ triggers a burst of ATP (1) VT Rx 1 Burst, cycle length of $280 \mathrm{~ms}$ ). This results in an acceleration

order to quantify the level of risk for drivers with cardiac disorders and to provide an objective and theoretical method for assigning risk to a driver [8]. The RH analysis was performed based upon the data from the early Ontario Road Safety Annual Report [29]; it is important to understand that there may be some differences among geographic areas due to the variation in the population density, driving habits, and type of vehicles. Although we have no data on the driving parameters (i.e., TD, V, or Ac) in Japan, it is feasible to implement contemporary area-specific driving parameters to calculate the RH to other users of the road. Driving restrictions are useful to protect the society from harm, but they should be balanced

(a)

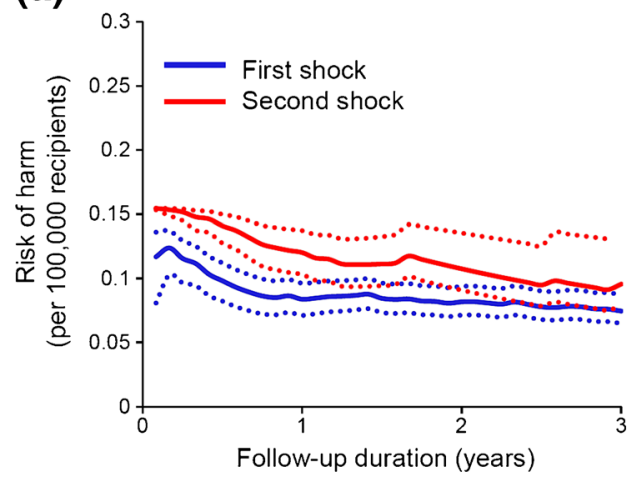

Fig. 3 The annual risk of harm from an inappropriate ICD therapy. The risk of harm (solid lines) is calculated in years following the implantation or following the first inappropriate shock. The dotted lines represent the 95\% confidence interval. a Primary prevention. Driving is acceptable directly following an implantation (blue line) $(0.11 / 100,000)$ or to a tachycardia with a 250 to $320-\mathrm{ms}$ cycle length, with a subsequent burst of ATP (2) VF Rx 1 Burst During Charging, cycle length of $250 \mathrm{~ms}$ ). This therapy degenerated the VT into $\mathrm{VF}$, which required shock therapy for termination (3) $35.3 \mathrm{~J}$ ). His creatinine was $12.1 \mathrm{mg}$ / $\mathrm{dL}$, and serum potassium was $7.0 \mathrm{mmol} / \mathrm{L}$ at admission. The upper and lower electrograms are continuous recordings. ATP antitachycardia pacing, $V T$ ventricular tachycardia, $V F$ ventricular fibrillation

against the QOL of the ICD patients, which may be reduced by unnecessary driving restrictions. To accomplish this, up to date clinical evidence is required.

In this study, there were 5 episodes of VT and 12 episodes of VF as a result of inappropriate ICD therapies. Of those, two patients lost consciousness due to inappropriate ICD therapies for SVTs or abnormal sensing degenerating into VF. While ATP is highly effective in terminating VT and lowers the use of high-energy shocks, ATP may degenerate stable arrhythmias into VF and hence result in incapacity prior to the delivery of the shock $[11,34,35]$. A prospective study of 770 primary and secondary prevention ICD patients revealed that

(b)

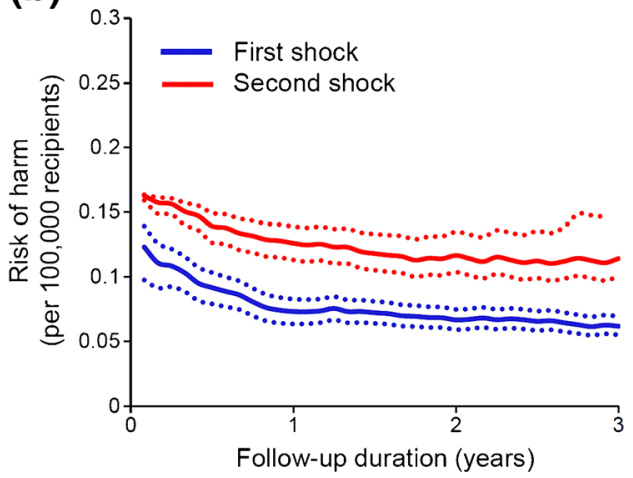

following the first inappropriate shock (red line) $(0.15 / 100,000)$. b Secondary prevention. Driving is acceptable directly following an implantation (blue line) $(0.12 / 100,000)$ or following the first inappropriate shock (red line) $(0.16 / 100,000)$ 
in patients receiving ATP for termination of a fast VT, syncope occurred in $0.2 \%$ of cases [35]. In the PITAGORA ICD trial, the incidence of a fast VT-related syncope following ATP was $0.97 \%$ [36]. These observations were similar to the rates observed in our study.

In this study, one patient experienced a shock while driving a motor vehicle, but did not report any syncope nor cause a traffic accident. An observational study of 241 ICD patients followed for 36 months found that $5 \%$ of secondary prevention patients had ICD shocks while driving but did not report any syncope during these shocks [6]. Data from the Antiarrhythmics Versus Implantable Defibrillators trial showed that $8 \%$ of drivers experienced ICD shocks while driving without leading to an accident on the road [11]. According to an early survey of ICD implanting physicians in the USA, there were a total of 30 motor vehicle accidents related to shocks from ICDs over a 12-year period [4]. Of those, nine were fatal accidents (eight patients with ICDs died); further, the estimated motor vehicle fatality rate for patients with ICDs of 7.5/100,000 patient-years was significantly lower than that for the general population (18.4/ 100,000 patient-years). From these results, we can conclude that ICD patients with secondary prevention may experience vehicle accidents due to arrhythmias or ICD discharges, but the occurrence rate is quite small, and the relative safety of driving with ICDs is supported [19, 37]. Few studies, however, have specifically examined the rate of syncope or ICD discharges while driving in patients receiving ICDs for primary prevention.

\subsection{Study limitations}

This study was a retrospective observation, and there are confounders associated with such a study method. Underreporting is another limitation since the occurrence of syncope was determined by only a chart review. It has been well documented that patients often drive despite instructions not to do so, and it can be anticipated that they do not tell doctors about symptoms if they think reporting would lead to curtailment of their driving. Because of the long time span, going back to 1997 , there is a heterogeneous patient population with regard to programming, but it is certainly encouraging to see a low event rate given the change in the detection algorithms and recommendations for programming for a shock reduction that has occurred in the more recent years. Data regarding the device therapies have been reported by the participating electrophysiologists and were not adjudicated by an independent committee. ICD programming was left to the discretion of each investigator. We could not assess the drivers' licensing, driving habits, and driving times. A near syncopal event while driving may result in a motor vehicle accident, but we did not collect data on near syncope. We do not have data on the rate of post mortem interrogations. Earlier ICDs were not equipped with EGM storage, and the programming options were limited. We collected data back to 1997 and ascertained that all ICDs in this study were equipped with EGMs. However, a more contemporary cohort would provide a more accurate estimation of the current risks. It is important to compare the rate of syncope between inappropriate and appropriate therapies, and the risk of harm. In the present study, however, we focused on the rate of syncope associated with inappropriate ICD therapy. Actually, we examined the number of appropriate therapies in this population, but we did not try to determine the rate or cause of syncope associated with appropriate ICD therapies. We will examine the rate of syncopal events associated with appropriate ICD therapy in the near future.

\section{Conclusions}

We demonstrated that a small number of patients $(0.7 \%)$ experienced syncope associated with inappropriate ICD therapies, with an estimated maximum annual risk of harm that was far below the commonly cited acceptable risk threshold of 5 in 100,000 . This observation suggests that in the case of private driving habits, there may be no need for driving restrictions following inappropriate ICD therapies, if it is not associated with a loss of consciousness.

Acknowledgements The authors thank Ms. Yoko Sato at the JHRS and Mr. Masaru Yamamoto and Dr. Yoshihiro Sobue for the data management. This work was supported by JSPS KAKENHI Grant Number $17 \mathrm{~K} 09533$.

\section{Compliance with ethical standards}

Conflict of interest Dr. Kurita discloses being on the speakers' bureaus for Daiichi-Sankyo, Bayer Schering Pharma, Bristol Myers, Boehringer Ingelheim, Medtronic Japan, St. Jude Medical Japan, and Biotronik Japan. All other authors have no disclosures for this work.

Open Access This article is distributed under the terms of the Creative Commons Attribution 4.0 International License (http:// creativecommons.org/licenses/by/4.0/), which permits unrestricted use, distribution, and reproduction in any medium, provided you give appropriate credit to the original author(s) and the source, provide a link to the Creative Commons license, and indicate if changes were made.

\section{References}

1. Moss AJ, Zareba W, Hall WJ, Klein H, Wilber DJ, Cannom DS, et al. Prophylactic implantation of a defibrillator in patients with myocardial infarction and reduced ejection fraction. N Engl J Med. 2002;346(12):877-83. doi:10.1056/NEJMoa013474.

2. Parsons M. Fits and other causes of loss of consciousness while driving. QJM. 1986;58(227):295-303.

3. Ostrom M, Eriksson A. Natural death while driving. J Forensic Sci. 1987;32(4):988-98. 
4. Curtis AB, Conti JB, Tucker KJ, Kubilis PS, Reilly RE, Woodard DA. Motor vehicle accidents in patients with an implantable cardioverter-defibrillator. J Am Coll Cardiol. 1995;26(1):180-4.

5. Bansch D, Brunn J, Castrucci M, Weber M, Gietzen F, Borggrefe $\mathrm{M}$, et al. Syncope in patients with an implantable cardioverter-defibrillator: incidence, prediction and implications for driving restrictions. J Am Coll Cardiol. 1998;31(3):608-15.

6. Trappe HJ, Wenzlaff P, Grellman G. Should patients with implantable cardioverter-defibrillators be allowed to drive? Observations in 291 patients from a single center over an 11-year period. J Interv Card Electrophysiol. 1998;2(2):193-201.

7. Freedberg NA, Hill JN, Fogel RI, Prystowsky EN, Group C. Recurrence of symptomatic ventricular arrhythmias in patients with implantable cardioverter defibrillator after the first device therapy: implications for antiarrhythmic therapy and driving restrictions. CARE Group. J Am Coll Cardiol. 2001;37(7):1910-5.

8. Simpson C, Dorian P, Gupta A, Hamilton R, Hart S, Hoffmaster B, et al. Assessment of the cardiac patient for fitness to drive: drive subgroup executive summary. Can J Cardiol. 2004;20(13): 1314-20.

9. Thijssen J, Borleffs CJ, van Rees JB, de Bie MK, van der Velde ET, van Erven L, et al. Driving restrictions after implantable cardioverter defibrillator implantation: an evidence-based approach. Eur Heart J. 2011;32(21):2678-87. doi:10.1093/eurheartj/ ehr161.

10. Sorajja D, Shen WK. Driving guidelines and restrictions in patients with a history of cardiac arrhythmias, syncope, or implantable devices. Curr Treat Options Cardiovasc Med. 2010;12(5):443-56. doi:10.1007/s11936-010-0088-3.

11. Klein RC, Raitt MH, Wilkoff BL, Beckman KJ, Coromilas J, Wyse DG, et al. Analysis of implantable cardioverter defibrillator therapy in the Antiarrhythmics Versus Implantable Defibrillators (AVID) trial. J Cardiovasc Electrophysiol. 2003;14(9):940-8.

12. Buber J, Luria D, Gurevitz O, Bar-Lev D, Eldar M, Glikson M. Safety and efficacy of strategic implantable cardioverterdefibrillator programming to reduce the shock delivery burden in a primary prevention patient population. Europace. 2014;16(2): 227-34. doi:10.1093/europace/eut302.

13. Tan VH, Wilton SB, Kuriachan V, Sumner GL, Exner DV. Impact of programming strategies aimed at reducing nonessential implantable cardioverter defibrillator therapies on mortality: a systematic review and meta-analysis. Circ Arrhythm Electrophysiol. 2014;7(1):164-70. doi:10.1161/CIRCEP.113.001217.

14. Daubert JP, Zareba W, Cannom DS, McNitt S, Rosero SZ, Wang P, et al. Inappropriate implantable cardioverter-defibrillator shocks in MADIT II: frequency, mechanisms, predictors, and survival impact. J Am Coll Cardiol. 2008;51(14):1357-65. doi:10.1016/j. jacc.2007.09.073.

15. van Rees JB, Borleffs CJ, de Bie MK, Stijnen T, van Erven L, Bax $\mathrm{JJ}$, et al. Inappropriate implantable cardioverter-defibrillator shocks: incidence, predictors, and impact on mortality. J Am Coll Cardiol. 2011;57(5):556-62. doi:10.1016/j.jacc.2010.06.059.

16. Banning AS, Ng GA. Driving and arrhythmia: a review of scientific basis for international guidelines. Eur Heart J. 2013;34(3):236- 44. doi:10.1093/eurheartj/ehs356.

17. Epstein AE, Miles WM, Benditt DG, Camm AJ, Darling EJ, Friedman PL, et al. Personal and public safety issues related to arrhythmias that may affect consciousness: implications for regulation and physician recommendations: a medical/scientific statement from the American Heart Association and the North American Society of Pacing and Electrophysiology. Circulation. 1996;94(5): 1147-66. doi:10.1161/01.cir.94.5.1147.

18. Epstein AE, Baessler CA, Curtis AB, Estes NA 3rd, Gersh BJ, Grubb B, et al. Addendum to "Personal and public safety issues related to arrhythmias that may affect consciousness: implications for regulation and physician recommendations. A medical/ scientific statement from the American Heart Association and the North American Society of Pacing and Electrophysiology". Public safety issues in patients with implantable defibrillators. A Scientific statement from the American Heart Association and the Heart Rhythm Society. Heart Rhythm. 2007;4(3):386-93. doi:10.1016/j. hrthm.2007.01.015.

19. Task force members, Vijgen J, Botto G, Camm J, Hoijer CJ, Jung W, et al. Consensus statement of the European Heart Rhythm Association: updated recommendations for driving by patients with implantable cardioverter defibrillators. Europace. 2009;11(8): 1097-107. doi:10.1093/europace/eup112.

20. Driver and Vehicle Licensing Agency. Assesing fitness to drive: a guide for medical professionals. 2017. https://www.gov.uk/ government/uploads/system/uploads/attachment_data/file/435071/ aagv1.pdf. Accessed April, 12017.

21. The National Police Agency. A revision to the Japanese Road Traffic Act (in Japanese). 2014. http://new.jhrs.or.jp/guideline/ statement150630/ http://www.npa.go.jp/pdc/notification/koutuu/ menkyo/menkyo20160930-146.pdf. Accessed April, 12017.

22. Watanabe E, Abe H, Watanabe S. Driving restrictions in patients with implantable cardioverter defibrillators and pacemakers. Journal of Arrhythmia. 2017;(in press). doi:10.1016/j. joa.2017.02.003.

23. Wilkoff BL, Williamson BD, Stern RS, Moore SL, Lu F, Lee SW, et al. Strategic programming of detection and therapy parameters in implantable cardioverter-defibrillators reduces shocks in primary prevention patients: results from the PREPARE (Primary Prevention Parameters Evaluation) study. J Am Coll Cardiol. 2008;52(7):541-50. doi:10.1016/j.jacc.2008.05.011.

24. Gasparini M, Menozzi C, Proclemer A, Landolina M, Iacopino S, Carboni A, et al. A simplified biventricular defibrillator with fixed long detection intervals reduces implantable cardioverter defibrillator (ICD) interventions and heart failure hospitalizations in patients with non-ischaemic cardiomyopathy implanted for primary prevention: the RELEVANT [Role of long dEtection window programming in patients with LEft VentriculAr dysfunction, Non-ischemic eTiology in primary prevention treated with a biventricular ICD] study. Eur Heart J. 2009;30(22):2758-67. doi:10.1093/eurheartj/ ehp247.

25. Moss AJ, Schuger C, Beck CA, Brown MW, Cannom DS, Daubert JP, et al. Reduction in inappropriate therapy and mortality through ICD programming. N Engl J Med. 2012;367(24):2275-83. doi:10. 1056/NEJMoa1211107.

26. Saeed M, Hanna I, Robotis D, Styperek R, Polosajian L, Khan A, et al. Programming implantable cardioverter-defibrillators in patients with primary prevention indication to prolong time to first shock: results from the PROVIDE study. J Cardiovasc Electrophysiol. 2014;25(1):52-9. doi:10.1111/jce.12273.

27. Kurita T, Noda T, Nitta T, Furushima H, Shimizu A, Ohe T, et al. Nippon storm study design. J Arrhythm. 2012;28(5):277-9. doi:10. 1016/j.joa.2012.04.003.

28. Watanabe E, Kasai A, Fujii E, Yamashiro K, Brugada P. Reliability of implantable cardioverter defibrillator home monitoring in forecasting the need for regular office visits, and patient perspective. Japanese HOME-ICD Study. Circ J. 2013;77(11):2704-11.

29. Road Safety Annual Report. Ontario Ministry of Transportation. Toronto 1987.

30. Merchant FM, Hoskins MH, Benser ME, Roberts G, Bastek AN, Knezevic A, et al. Time course of subsequent shocks after initial implantable cardioverter-defibrillator discharge and implications for driving restrictions. JAMA Cardiol. 2016;1(2):181-8. doi:10. 1001/jamacardio.2015.0386

31. Poole JE, Johnson GW, Hellkamp AS, Anderson J, Callans DJ, Raitt MH, et al. Prognostic importance of defibrillator shocks in patients with heart failure. N Engl J Med. 2008;359(10):1009-17. doi:10.1056/NEJMoa071098. 
32. Proclemer A, Ghidina M, Gregori D, Facchin D, Rebellato L, Fioretti P, et al. Impact of the main implantable cardioverterdefibrillator trials in clinical practice: data from the Italian ICD registry for the years 2005-07. Europace. 2009;11(4):465-75. doi: 10.1093/europace/eun370.

33. Exposito V, Rodriguez-Manero M, Gonzalez-Enriquez S, Arias MA, Sanchez-Gomez JM, Andres La Huerta A, et al. Primary prevention implantable cardioverter-defibrillator and cardiac resynchronization therapy-defibrillator in elderly patients: results of a Spanish multicentre study. Europace. 2016;18(8):1203-10. doi:10.1093/europace/euv337.

34. Pinski SL, Fahy GJ. The proarrhythmic potential of implantable cardioverter-defibrillators. Circulation. 1995;92(6):1651-64.

35. Martins RP, Blangy H, Muresan L, Freysz L, Groben L, Zinzius PY, et al. Safety and efficacy of programming a high number of antitachycardia pacing attempts for fast ventricular tachycardia: a prospective study. Europace. 2012;14(10):1457-64. doi:10.1093/ europace/eus107.

36. Gulizia MM, Piraino L, Scherillo M, Puntrello C, Vasco C, Scianaro MC, et al. A randomized study to compare ramp versus burst antitachycardia pacing therapies to treat fast ventricular tachyarrhythmias in patients with implantable cardioverter defibrillators: the PITAGORA ICD trial. Circ Arrhythm Electrophysiol. 2009;2(2):146-53. doi:10.1161/CIRCEP.108.804211.

37. Albert CM, Rosenthal L, Calkins H, Steinberg JS, Ruskin JN, Wang P, et al. Driving and implantable cardioverter-defibrillator shocks for ventricular arrhythmias: results from the TOVA study. J Am Coll Cardiol. 2007;50(23):2233-40. doi:10.1016/ j.jacc.2007.06.059. 